13

\title{
Многострийные кольцевые полевые эмиттеры с защитными металл-фуллереновыми покрытиями
}

\author{
( Г.Г. Соминский, ${ }^{1}$ Т.А. Тумарева, ${ }^{1}$ Е.П. Тарадаев, ${ }^{1}$ А.А. Рукавицына, ${ }^{1}$ М.Е. Гиваргизов, ${ }^{2}$ А.Н. Степанова ${ }^{2}$ \\ ${ }^{1}$ Санкт-Петербургский политехнический университет Петра Великого, \\ 195251 Санкт-Петербург, Россия \\ ${ }^{2}$ Институт кристаллографии РАН, \\ 119333 Москва, Россия \\ e-mail: sominski@rphf.spbstu.ru
}

(Поступило в Редакцию 26 марта 2018 г.)

Разработана методика создания многоострийных кольцевых полевых эмиттеров из кремния с двухслойным металл-фуллереновым покрытием и исследована их работа. Кольцевые эмиттеры площадью $\sim 0.3 \mathrm{~cm}^{2}$ обеспечивают токи до $100-110 \mathrm{~mA}$ и стабильно работают в условиях технического вакуума $\sim 10^{-7}$ Torr.

DOI: $10.21883 /$ JTF.2019.02.47086.124-18

\section{Введение}

Существуют и привлекают к себе все больший интерес миниатюрные, но высоковольтные электронные приборы, где трудно использовать накаливаемые термокатоды. К таковым можно отнести, например, коротковолновые электронно-лучевые СВЧ-устройства $[1,2]$. Кажется заманчивой замена термокатодов в таких приборах холодными полевыми эмиттерами.

В последние годы были созданы (см., например, [3-6]) эффективные полевые эмиттеры, позволяющие получать необходимые для указанных приложений токи порядка десятков миллиампер и плотности токов полевой эмиссии $\geq 100-150 \mathrm{~mA} / \mathrm{cm}^{2}$. Но, к сожалению, до сих пор не доказана возможность длительной эксплуатации созданных эмиттеров в высоковольтных электронных приборах при отборе больших токов в условиях технического вакуума. В существующих „распределенных“ многоострийных или лезвийных полевых эмиттерах удается уменьшить токовую нагрузку на отдельный эмиссионный центр и таким образом снизить воздействие на эмиттер тепловых эффектов, связанных с протеканием токов через эмиссионные центры. Однако пока не удается исключить разрушающее действие интенсивной в техническом вакууме ионной бомбардировки.

При использовании катодов Спиндта [2] делались попытки уменьшить интенсивность ионной бомбардировки катода с помощью специальных электронно-оптических систем, препятствующих попаданию на его поверхность ионов из канала транспортировки сформированного с использованием полевого эмиттера электронного пучка. Но при этом не исключалась бомбардировка катода быстрыми ионами, рожденными на участке ускорения электронов перед входом в канал транспортировки. В последние годы были разработаны конструкции миниатюрных трехэлектродных автоэлектронных структур с ионной защитой эмиттера [7]. Электронно-оптическая система таких структур по замыслу разработчиков должна исключить попадание на катод ионов, образованных в самой структуре, но сомнительно, что электрические поля в таких структурах малого размера могут эффективно защитить эмиттер от бомбардировки ионами с энергией больше нескольких сотен вольт, возникающих на участке ускорения электронов вне катодной структуры.

Иной достаточно эффективный метод защиты полевых эмиттеров от разрушающего действия ионной бомбардировки был предложен и реализован в СанктПетербургском политехническом университете [8,9]. На поверхности эмиттеров создавалось тонкое покрытие из молекул фуллерена $\mathrm{C}_{60}$ толщиной 2-3 монослоя $(\mathrm{ml})$. Исследования показали, что быстрые ионы, бомбардирующие катод, практически не разрушают и не десорбируют молекулы покрытия, а большую часть своей энергии выделяют в подложке. Медленные частицы подложки, высвободившиеся под действием ионной бомбардировки, не могут преодолеть покрытие и удерживаются на поверхности подложки. Авторами $[8,9]$ была исследована работа одноострийных эмиттеров из вольфрама с защитными фуллереновыми покрытиями. Такие эмиттеры с диаметром вершины порядка $100 \mathrm{~nm}$ стабильно работали в техническом вакууме при отборе токов полевой эмиссии не более 50-100 $\mu \mathrm{A}$. Как было недавно продемонстрировано в работах [10-12], в условиях технического вакуума стабильную эмиссию 50-100 mА при плотностях тока ориентировочно до $0.4 \mathrm{~A} / \mathrm{cm}^{2}$ могут обеспечить многоострийные кремниевые структуры с двухслойным металл-фуллереновым покрытием. Учитывая достигнутые успехи в разработке и исследовании таких структур, авторами [1] была предложена концепция создания электронно-оптических систем с полевыми эмиттерами такого типа для формирования электронных потоков в диагностических гиротронах. Для реализации этой концепции необходимы кольцевые эмиттеры. В настоящей работе описана разработанная авторами методика создания многоострийных кольцевых полевых эмиттеров из кремния с двухслойным металлфуллереновым покрытием и исследована их работа. 


\section{Методы создания и исследования многоострийных кольцевых эмиттеров с двухслойным металл-фуллереновым покрытием}

Согласно разработанной в [1] концепции, электронный поток для диагностических гиротронов должен формироваться с помощью электронной пушки с плоским кольцевым эмиттером, схематически изображенной на рис. 1. В электронно-оптической системе формирования электронного потока поле у поверхности катода, необходимое для полевой эмиссии, создается при подаче отрицательного напряжения $U$ на катодную систему 1 относительно анода 2 с кольцевой диафрагмой. Для реализации такой конструкции источника электронов кольцевые эмиттеры должны иметь центральное отверстие, необходимое для крепления одного из электродов анодной системы.

Кольцевые эмиттеры создавались на основе однородных по площади кремниевых пластин с упорядоченной структурой острий на поверхности, изготовленных с использованием хорошо отработанной ранее технологии $[11,12]$.

Двухслойные металл-фуллереновые покрытия наносились по методике, описанной в [12], непосредственно в вакуумной установке, использованной для исследования эмиттеров. Морфология поверхности катодов контролировалась с помощью растрового электронного микроскопа типа SUPRA 55VP-25-87 до их установки в измерительную установку и после завершения измерений.

Для обеспечения достаточно высокой проводимости и повышения прочности многоострийных структур на их поверхность наносилось молибденовое покрытие. Толщина молибденового покрытия для кремниевых структур с разным радиусом вершины острий менялась в пределах приблизительно от 5 до $20 \mathrm{~nm}$ и выбиралась

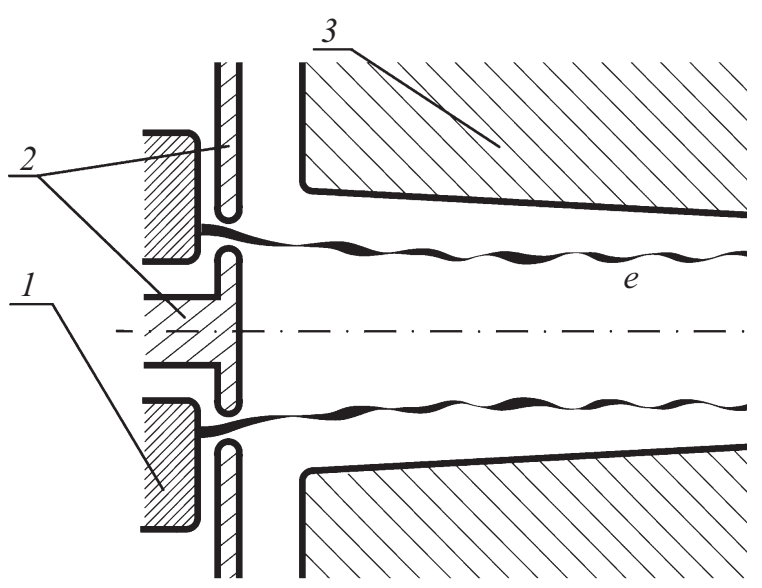

Рис. 1. Схематическое изображение сечения проектируемой электронной пушки с кольцевым полевым эмиттером [1]: 1 катодная система с полевым эмиттером на торце, 2 - детали анода с кольцевой диафрагмой, 3 - канал транспортировки электронного пучка $e$.
Характеристики исследованных катодов

\begin{tabular}{c|c|c|c}
\hline \multicolumn{2}{c|}{$C 1$} & \multicolumn{2}{c}{$C 2$} \\
\hline$D, \mathrm{~mm}$ & $d, \mathrm{~mm}$ & $D, \mathrm{~mm}$ & $d, \mathrm{~mm}$ \\
\hline 7 & 1.3 & 14 & 0.65
\end{tabular}

таким образом, чтобы суммарный радиус $R$ вершины острий (с учетом покрытия) не превышал 20-30 nm. Защитное фуллереновое покрытие толщиной $2 \mathrm{ml}$ напылялось поверх металлизации. Расстояние между остриями для всех исследованных образцов имело величину около $30 \mu \mathrm{m}$. Высота $h$ острий варьировала для разных образцов в пределах $30 \leq h \leq 60 \mu \mathrm{m}$.

Центральное отверстие в кремниевой пластине вырезалось с помощью лазера. Острия над внешней границей эмитирующего пояска устранялись с помощью лазерной абляции.

На рис. 2 приведены схематические изображения исследованных кольцевых структур (рис. 2,a) и диодной системы, использованной для измерения эмиссионных характеристик катодов (рис. 2,b). Пластина из кремния 1 с кольцевой многоострийной структурой имела толщину $430 \mu \mathrm{m}$. Она крепилась на держателе катода 2 с подогревателем 3, который использовался для обезгаживания катода; 4 - анод измерительной системы.

Были изготовлены и исследованы два типа катодов: $C 1$ и $C 2$. Эти кольцевые эмиттеры отличались средним диаметром $D$ и шириной $d$ эмитирующего пояска (рис. 2, $a$ ), но имели приблизительно одинаковую площадь эмитирующей поверхности $S \sim 0.3 \mathrm{~cm}^{2}$. Значения $D$ и $d$ эмиттеров $C 1$ и $C 2$ приведены в таблице.

При исследовании катодов типа $C 1$ плоский анод располагался на расстоянии $1.5 \mathrm{~mm}$ от катода. В диодной системе, использованной для измерения характеристик катодов типа $C 2$, анод располагался на расстоянии $2.0 \mathrm{~mm}$ от катода.

Экспериментальная вакуумная система подвергалась непрерывной откачке. После отжига деталей установки обеспечивалось минимальное давление остаточных газов порядка $10^{-9}-10^{-10}$ Torr.

Установка была оснащена системой напуска азота, с помощью которой можно было оперативно менять давление от указанного выше минимального до $10^{-6}$ Torr и обратно. Формирование покрытий эмиттеров производилось при давлении около $10^{-9}$ Torr. Исследование же эмиссионных характеристик катодов проводилось в техническом вакууме при повышенных давлениях $\sim 10^{-7}$ Torr.

\section{Результаты измерений}

Измерялись вольт-амперные характеристики катодов, а также изменения токов полевой эмиссии во время их 
$a$

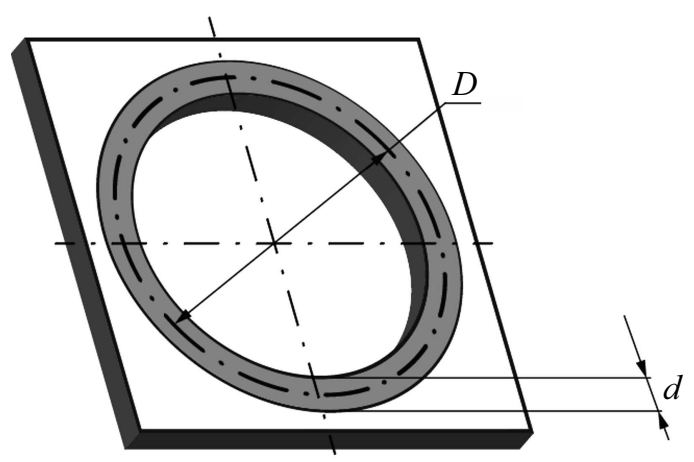

$b$

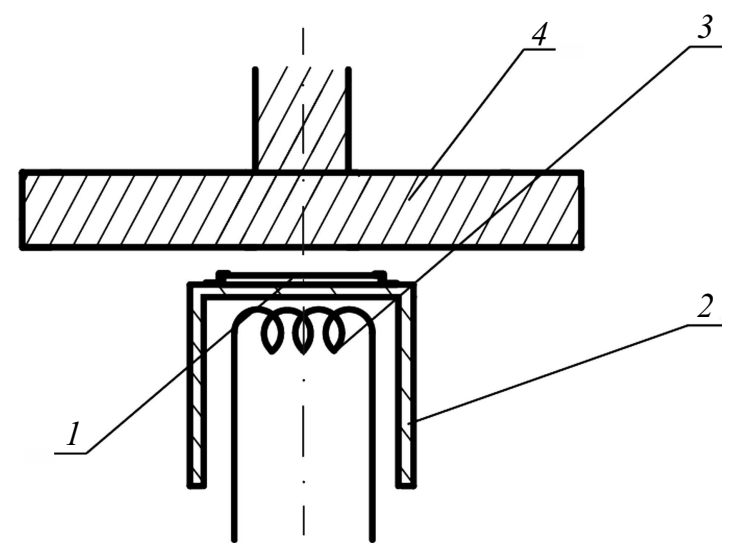

Рис. 2. Схематические изображения исследованных кольцевых структур $(a)$ и диодной системы $(b)$, использованной для измерения эмиссионных характеристик катодов.
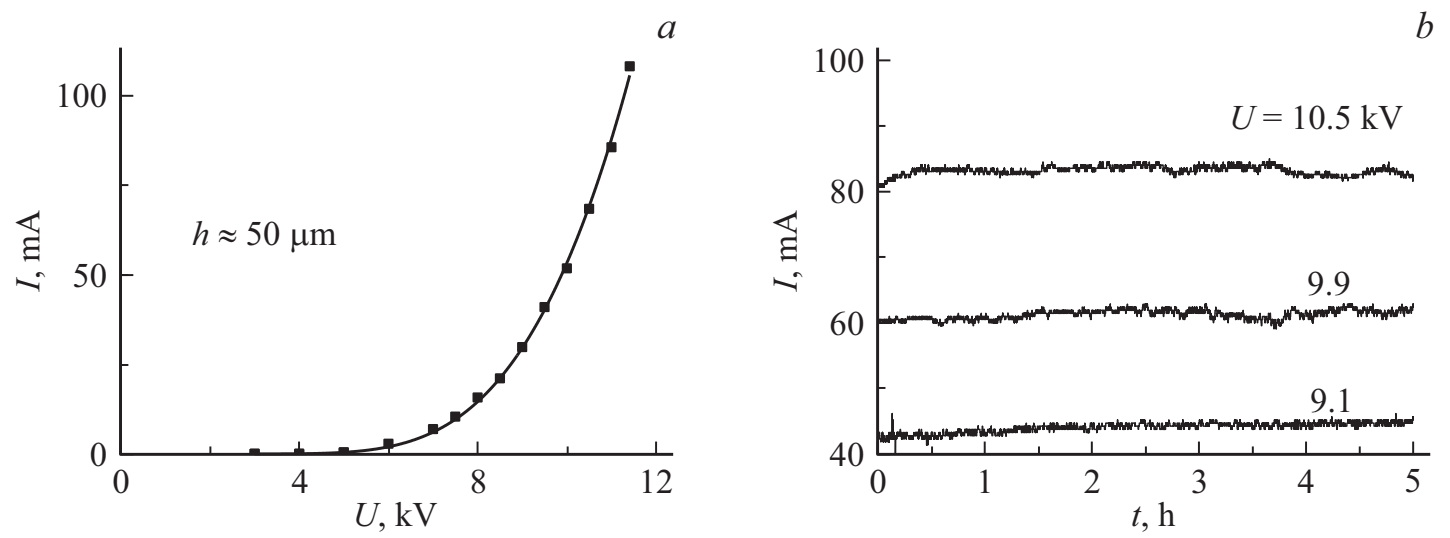

Рис. 3. Типичные характеристики кольцевого катода $C 1$ : вольт-амперная кривая $(a)$ и зависимости тока эмиссии от времени эксплуатации $(b)$.

эксплуатации в техническом вакууме. Измерения эмиссионных характеристик в статическом режиме выполнялись при токах с катода, не превышающих 1.0-1.5 mA. Чтобы свести к минимуму нагрев катода и анодаколлектора, измерения при больших токах проводились в импульсном режиме $(1 \mu \mathrm{s}, 50-500 \mathrm{~Hz})$. Электрические поля, необходимые для формирования полевой эмиссии с катода, создавались при подаче на катод отрицательного относительно коллектора напряжения $U$. Ток электронов $I$ измерялся в цепи коллектора. Временные изменения тока эмиссии контролировались с помощью электронного самописца типа Velleman PCS10.

На рис. 3 показаны типичные характеристики кольцевого катода (вольт-амперная кривая $(a)$ и зависимости токов эмиссии от времени эксплуатации $(b))$. В исследованных режимах токи полевой эмиссии достигали 100-110 mА. При этом средние по поверхности катода плотности токов не превышали $\sim 400 \mathrm{~mA} / \mathrm{cm}^{2}$. Исследованные кольцевые катоды стабильно работали в техническом вакууме.

\section{Заключение}

Подытоживая результаты работы, отметим главное:

- разработана достаточно простая методика формирования многоострийных кольцевых эмиттеров с двухслойными металл-фуллереновыми покрытиями;

- экспериментально продемонстрирована возможность обеспечения с помощью созданных эмиттеров стабильной работы высоковольтных электронных приборов в условиях технического вакуума $\left(\sim 10^{-7}\right.$ Torr $)$ при отборе с эмиттера площадью $0.3 \mathrm{~cm}^{2}$ токов полевой эмиссии до $100-110 \mathrm{~mA}$ при плотности тока до $400 \mathrm{~mA} / \mathrm{cm}^{2}$.

Созданные эмиттеры перспективны для использования в электронно-пучковых СВЧ-приборах коротковолнового миллиметрового и субмиллиметрового диапазонах длин волн.

Настоящая работа финансировалась грантом РНФ № 16-12-10010. 


\section{Список литературы}

[1] Glyavin M.Yu., Manuilov V.N., Sominskii G.G., Taradaev E.P., Tumareva T.A. // Infrared Phys. Techn. 2016. Vol. 78. P. $185-189$.

[2] Whaley D.R., Duggal R., Armstrong C.M. et al. // IEEE Tr. Electron. Dev. 2009. Vol. 56. N 5. P. 896-905.

[3] Chen Z., Cao G., Zhang Q. et al. // Nanotechnology. 2007. Vol. 18. N 9. P. 095604.

[4] Chen Z., Zhang Q., Lan P. et al. // Nanotechnology. 2007. Vol. 18. N 26. P. 265702.

[5] Chi Li, Yan Zhang, Mark Mann et al. // Appl. Phys. Lett. 2010. Vol. 97. N 11. P. 113107.

[6] Бушуев Н.А., Глухова О.Е., Григорьев Ю.А., Иванов Д.В., Колесникова А.С., Николаев А.А., Шалаев П.Д., Шестеркин В.И. // ЖТФ. 2016. Т. 86. Вып. 2. С. 134.

[7] Абаньшин Н.П., Горфинкель Б.И., Морев С.П., Мосияш Д.С., Якунин А.Н. // Письма в ЖТФ. 2014. Т. 40. Вып. 9. C. 86-94.

[8] Тумарева Т.А., Соминский Г.Г., Ефремов А.А., Поляков А.С. // ЖТФ. 2002. Т. 72. Вып. 2. С. 105.

[9] Тумарева Т.А., Соминский Г.Г. // ЖТФ. 2013. Т. 83. Вып. 7. C. 121.

[10] Соминский Г.Г., Тарадаев Е.П., Тумарева Т.А. Патент на полезную модель RU 151235 „Острийный полевой эмиттер“. Опубликовано 27.03.2015.

[11] Соминский Г.Г., Тумарева Т.А., Тарадаев Е.П., Мишин М.В., Степанова А.Н. // ЖТФ. 2015. Т. 85. Вып. 1. C. $138-141$.

[12] Соминский Г.Г., Тарадаев Е.П., Тумарева Т.А., Гиваргизов М.Е., Степанова А.Н. // ЖТФ. 2016. Т. 86. Вып. 11. C. $108-111$. 